Running head: CLAIMING JUSTICE

\author{
Claiming justice: victims of crime and their perspectives of justice \\ Robyn L. Holder ${ }^{1}$ and Amanda Robinson ${ }^{2}$ \\ ${ }^{1}$ Griffith University, Australia \\ ${ }^{2}$ Cardiff University, Wales
}

\begin{abstract}
Authors' Note
Correspondence should be addressed to Robyn Holder, Griffith Criminology Institute, Mt Gravatt Campus, Griffith University, 176 Messines Ridge Road, Mt Gravatt, Queensland 4122, Australia. Tel: +61(0)7 37353440 E-mail: r.holder@griffith.edu.au
\end{abstract}

This is a pre-publication version of an article submitted for publication to the Sage journal, International Review of Victimology. Please refer to the published version for correct page citations.

(C) Robyn Holder \& Amanda Robinson 22 October, 2020 


\begin{abstract}
Victims claiming justice has surface simplicity but arises in a range of contexts influenced by different histories, facing different institutions offering different possibilities. It is this tremendous range of contexts and characteristics that have engaged researchers. Most have taken the idea of justice as a given. As guest editors of this symposium on justice, we sought to delve into deeper and under-explored dimensions including the interconnection of inequality and justice, the relationship between public and private justice, the interests that victims have in justice, and the interface between social and criminal justice for victims. The contributions are broad in scope and consider different victimization types and contexts, different justice mechanisms and pathways that victims pursue, and extend across domestic and international justice domains. We reflect on intersections and divergences, challenges for the field and opportunities and future directions for research.
\end{abstract}

Key words: Victims, justice, research, theory 


\section{Claiming justice: victims of crime and their perspectives of justice}

Placing the words 'victim' and 'justice' side by side raises numerous questions; questions about which victims and the nature of their victimization, and questions about the context to and consequences of the violation. Instead, we focus on questions about justice; its meanings (and for whom), its associations and institutional embodiments plus its contexts and consequences. The surface simplicity of justice as a word belies its dimensions, the plurality of its grounds, and the different criteria brought to evaluations of what is just or unjust. In cultural and normative senses, justice is an ideal, a promise and a vision, transcendent in its capacity and universal in its reach. As a word, justice drives social movements and rebellion. It is grasped by individuals, groups and communities in all their multiple shifting identifications. Confusingly, it is also tied (some would say, tied down) to particular institutions, to frameworks of laws and rules, and to culminations designed and produced by certain procedures. As a word, it is both solid and malleable.

This symposium engages with these varying ideas of justice. Each of the articles holds justice at its core but each discusses something different: the meanings of justice for victims of mass atrocity (Balde and Wemmers), how communities can imagine and shape their own forms of justice (Kim), how procedures designed for justice fall short (Messing, Bagwell-Gray, WardLasher and Durfee), and the grounded concepts of justice used by women with disabilities (McCulloch, Maher, Walklate, McGowan and Fitz-Gibbon). As guest editors we ask what these contributions bring to understanding the complex relationships that victims, in all their diversity and with all their diverse experiences, have with justice in its myriad meanings and forms. We reflect on shared concerns and divergences and consider the challenges that persist for 
researchers and advocates alike. We first briefly survey the research and debates about victims and justice.

\section{Victims, victimization and justice research}

Victimization surveys, conducted within and across countries for decades, have revealed both the nature and extent of people's experiences with 'everyday' crime and how this is unevenly distributed according to their gender, sexuality, age, race/ethnicity, socioeconomic status, and ability. Geographic variation is also apparent, with significant differences in the level and type of victimization observed at the neighbourhood, regional and national levels. Research of various types (household surveys, demographic estimates and small-scale studies) also reveals the nature and extent of victimization from more exceptional events; for example, the deaths, disappearances and dispossessions due to mass conflicts (for an overview, see Karstedt, 2013).

Studies have documented the impact of victimization, especially of violence and sexual victimization, and the corrosive effects on inter-personal and social relationships in everyday and mass crimes (Heap, 2020; Stover and Weinstein, 2004). These have identified the range of consequences - physical, emotional, material, social and financial - from the short to the longer term (Anderton, 2014; Mahuteau and Zhu, 2016). Finally, existing scholarship explores why, when and how victims turn to formal legal systems for help, demonstrating the many challenges facing victims of violence in particular (Holder, 2018a; Karstedt, 2017).

Nonetheless, victims' experiences with and aspirations for justice have captured the attention of researchers and advocates alike in local jurisdictions (see, for example, Shapland, Willmore and Duff, 1985) as well as in international tribunals (see, for example, Stover and Weinstein, 2004). These experiences with formal justice processes have been found wanting for victims of 
everyday crimes (Laxminarayan et al., 2013) and victims of mass atrocity alike (Hodžić, 2010; Rafferty, 2018). Difficulties claiming justice are particularly pronounced for those suffering intimate partner violence (Fugate et al., 2005; Robinson, 2014), sexual violence (Robinson and Hudson, 2011), human trafficking (Ren, 2014), child abuse (Eastwood, 2003) and homicide (Dawson, 2012; Englebrecht, Mason and Adams, 2014). In broad terms, the research about victim experiences concurs that people across many sites of victimization and in different justice contexts are kept poorly informed and are often not perceived to be meaningful actors within formal justice system processes and responses

\section{This symposium}

Contributors to this symposium traverse familiar ground with fresh eyes. Balde and Wemmers explore the meanings of justice to which victims of mass atrocity and human rights abuses give voice. Situations of mass violence may be exceptional in their occurrence yet as these researchers reveal, produce devastating consequences. Compounding the victimization experienced directly at the hands of perpetrators is the 'secondary' victimization that results from the complicity of state actors in condoning, even supporting, mass violence. For the population in Guinea, west Africa, severe violations of human rights were perpetrated by post-colonial governments and military rulers. Distrust and fear of authorities silenced many, both at the time and to this day. The widespread belief that successive groups of perpetrators appeared to enjoy a sense of impunity exacerbated the population's perception of a chronically corrupt justice system. In this environment, victims tried different ways of seeking justice at national and international levels; ranging from giving public voice to their victimization to participating in formal investigations and helping to design a special commission (p. 5). With this history and range of opportunities, Balde and Wemmers asked 31 Guineans what justice they sought. Using 
distributive, procedural and interactional justice theories to analyse the interview data, the authors found multi-dimensional understanding and aspirations. Accountability was identified as a uniform aspiration by their interviewees, which was to be realized through the punishment of offenders and reparation for victims. For these survivors of killings, rapes, torture, theft and confiscation, these aspirations were driven by a desire for specific and future deterrence and for recognition of the wrongs done (p.12). In claiming justice, all envisaged their necessary and meaningful inclusion in procedures that applied the law equally, fairly and universally (pp.1314). Recognition was a central and strong theme; both recognition of them as victims and recognition of their victimization. Recognition was foundational to their preferences for what should happen next and was viewed by victims as a demonstration of respect (pp.14-15). Knowing what mechanisms were available to achieve these goals was seen by victims to be critical for their assessments of which pathways to justice were viable for them; but the absence of information made this almost impossible (p.17).

For the victimized communities and groups in Kim's conceptual contribution, the impossibility of formal state-run justice for people of colour in the United States (U.S.) drives interest in nonstate developments. Kim directly links the rise of mass incarceration in the U.S. and its disproportionate impact on people and communities of colour to the strategic efforts of antidomestic violence advocates to engage police, prosecutors and courts in interventions against gender-based violence. Anti-oppression and anti-discrimination social movements are by their very nature anti-establishment. By their very nature they are also pro-reform and pro-justice. The divergence from these roots and its unintended consequences, Kim argues, has flowed from a reliance on the state machinery of criminal justice as a preeminent weapon to address the wrongs 
of violence against women and children but without dealing with entrenched racism within the system. Kim identifies a number of explanatory factors for this situation, including: that the antiviolence women's movement lost control over their agenda as a result of their collaboration with criminal justice agencies (p.6); that formal legal processes have been shown to consistently fail the underprivileged and those seeking help about violence (p.7); and that the promise of equality before the law fails repeatedly in diverse contexts (p.8). Part of the problem that Kim highlights is the contested notion of justice particularly when made concrete in institutionalized form. She draws on two social movement examples in the U.S. to suggest other ways forward. INCITE! evolved from activism by women of colour who were survivors of physical and sexual violence to condemn both gender-based violence and state violence (p.10); while generationFIVE seeks "collective, community-based responses to child sexual abuse and other forms of interpersonal violence" (p.11). Movements such as these, Kim argues, draw anti-violence strategies away from an anti-perpetrator and a carceral focus to reconnect with its liberatory origins.

The contribution from Messing and her colleagues also engages with the gap between the promise of legal protection and its realities. Their empirical study is located in the spaces opened by Kim; spaces where women victimized by violence exercise discretion to go their own way and not engage with formal legal processes. This study examines women's decisions not to apply for orders of protection. Their survey respondents, over 400 ethnically mixed women resident in one of 10 shelters in the Southwest U.S., were asked if they tried an order of protection (OP), which is the type of instrument that arguably enables women to retain some control over the conditions and outcomes they seek. For those who did not try for an OP, their responses coalesced on assessments that an order would not reduce or stop the violence, systemic barriers 
prevented their using the law or forestalled its access, that an OP was unnecessary or that other measures would be more effective, or that characteristics and dynamics of the abuse and its consequences for others were factors. Many of these concerns about civil justice mirror those found in other studies of women weighing up whether to engage with criminal justice. These concerns highlight that the law's promise is only one of a number of factors in decision-making about wrongs, harms and protection, and that the nature and context of the victimization experience itself necessarily gives rise to complex and dynamic decision-making for victims. In short, determining whether or not to apply for an OP is not a single 'choice', but instead one aspect of a multi-faceted decision-making process. Moreover, Messing et al.'s research highlights that simply making a new remedy or intervention available is only one step in a victim's journey towards safety. The possibility of achieving justice in such circumstances simply does not present itself as a realistic goal, let alone a priority for many victims.

For the women in the contribution from McCulloch and her colleagues, the possibility of justice was also just one of several objectives they sought after experiencing violent crime, often on multiple occasions and from a range of sources. Managing life with a disability was itself not always easy for the 36 women in this Australian study. The women observed that their status and inclusion as members of the community was circumscribed, their material circumstances often limited, and their social opportunities narrowed. Add violence and the hurdles became more pronounced (p.4). Violence itself is disabling; furthermore, violence compounds the experience of social marginalization that people with a disability experience. With this context, McCulloch and her colleagues highlight elemental components of human dignity following violence: being listened to; having oneself and one's experience acknowledged and validated; and, being 
believed (p.7). As with other studies, this contribution places a harsh light over those human agencies established to 'help', but which instead often end up hindering. The complexity of managing life on a day-by-day basis, as a woman with a disability, intersects with 'help' systems that can end up almost as controlling and blaming of them as those who perpetrated the abuse and violence (p.9-10). The idea of justice for these women is thus wider than the remedial and deeper than the correction of the wrong done to them.

\section{Meanings of justice}

As a collection, this symposium is broad in the depiction of the contexts surrounding victims' claims for justice and thus have generated different conceptualizations of justice. Beyond this collection, these differences can generate rich research and fruitful dialogue amongst researchers and advocates. They can also result in less fruitful arguments about what is 'better'; that one form/type/mechanism of justice should predominate, and others be abandoned; or that one approach to justice is more or less aligned with this or that grouping of people and their victimization experiences. Debates about differences and similarities are the lifeblood of research; but going deeper to explore assumptions and underpinnings could provide new lines of enquiry and unexpected overlaps with older studies and other disciplines. We think that central to future work is greater clarity of terms and more explicit engagement on their meanings and relevant theoretical origins.

As a starting point, we borrow the distinction between the 'concept' of justice and 'conceptions' from political philosopher, Adam Swift. The 'broadly agreed' 'general structure' of the concept, he writes, entails 'giving people what is due to them, and not giving them what is not due to them'. A conception, on the other hand, is a "particular specification of that "concept", obtained 
by filling out some of the detail' (Swift, 2014: 13). The idea of justice as giving people what is due to them creates a foundation from which to then explore the particulars of experience and perspective. What is 'due' is necessarily contextual, societal and contestable. For victims of violence, answering what is 'due' will also necessarily involve considering them, the perpetrators, and a raft of others (Holder and Daly, 2018). Then, the particulars will depend on standpoint - who or what is assessing? Critical theorists - feminist, critical race, Indigenous, queer, for example - all demand we pay attention to these questions. The particulars of justice will also depend on the 'good' that is at issue. For example, the good of freedom or the good of a specific social resource, both of which are relevant to the subjects in this symposium's contributions. ${ }^{1}$

Whether the distinction between the concept of justice and its conceptions can survive their use in the different disciplines that researchers in our field of victims of violence come from is a question. But explicit engagement with the disciplinary basis of justice research and their claims may help reveal some assumptions and related theoretical underpinnings for researchers to consider. The economic basis of distributive justice and the social psychological basis of procedural justice, for example, can reveal assumptions about utility (or what is valued) as well as the range of elements embedded within a procedure. Political scientists and legal theorists will explore the question of justice by foregrounding notions of institutional design and ideas about applying the 'correct' principles; and might agree that human beings and human societies in all

\footnotetext{
${ }^{1}$ The distribution of social resources has tended to consider material resources such as education, income or housing, for example, and has given rise to extensive debate about choices, preferences and societal inequities. Amartya Sen and Martha Nussbaum are two who have suggested that what people are able to do or able to be (their capabilities) is not about characteristics of the person but what enables people individually and collectively to function and flourish. For an overview see, for example, Nussbaum, M. and Sen, A. (1993) (Eds). The quality of life. Oxford University Press.
} 
their variation will determine what is right or fair in any given circumstance. From any of these disciplinary bases, with which criteria are we evaluating justice: for example, equity, equality, merit or desert (Sen, 2019)? Our thinking on the question of meaning-making about justice as guest editors is that it is not only an analytical choice by researchers designed for interpretive understanding but can - probably should - be made richer and more robust with relevant connections to larger bodies of thought.

\section{Common themes and future challenges}

We conclude by making some perhaps more grounded observations on common themes across contributions.

\section{The persistence of injustice and centrality of justice}

The symposium invited scholarly reflections on victims' claims for justice, but what emerges is the depth of feeling and commitment from scholars and respondents alike for justice.

Victimization and injustice in all its many forms do not always give rise to calls for justice - it is not an automatic action to take or connection to make - but the connection is deep. We cannot examine one without the other.

\section{Core elements and human dignity}

The contributions share, with differing degrees of emphasis, core elements to victims' quests for justice: recognition and acknowledgement, validation and vindication. Social psychologists and political theorists would tell us this is about group belonging and shared community, whilst also acknowledging that an individual does not necessarily belong to only one group or a single community. 
Not only the self

Many victims share interests in the righting of injustices and achieving justice. Common in the contributions is the finding that victims seek justice as a goal for others as well as for themselves; for children, for future generations, for their communities, for other survivors and even for perpetrators, as they too are due justice.

\section{Meaning making}

As already discussed, the contributions highlight the range of meanings that people attribute to the idea of justice. These are distributions and procedures, interactions and institutions. It is both subjective and objective; a group-based assessment and something assigned by a neutral third party. Justice assessments are an aggregation as well as specific decisions. But what are the theoretical associations that scholars are making and with what disciplinary assumptions? For a universalized concept, how individualized, how fragmented can justice be?

There are many future challenges to our shared interest in victims' claims for justice, what they are offered, what they receive, and what more they demand. Here we offer some observations:

\section{Accountability and punishment}

The contributions also shared, again with differing emphases, the importance to victims of accountability for wrongdoing. Described in the contributions as offender accountability, as imperative, and as supporting accountability. Whether the ones held to account are militia, government entities or individuals, the centrality of accountability to addressing injustice is 
apparent. What is also clear is that accountability needs to be detached from punishment. These things are not the same. They are not the same regardless of the type of justice mechanism through which accountability is attained.

\section{What of comparison?}

Much research on victims and their justice claims are context-specific and use singular methods. These are rich studies but we need to progress our understanding of differences and similarities. Do all victims in all contexts identify injustice in the same ways? What are the differing or similar characteristics to societal choices and pathways for justice claims? Do societies 'do justice' differently; how, when and why? Comparative studies on victims and justice are underdeveloped, perhaps because some core concepts remain too ill-defined by researchers to be robustly applied across contexts (Daly, 2017). Even within a single country, what are the criteria that can adjudicate research findings and debates on different justice responses, and on what criteria would the assessments be made? Moreover, how do we assess and compare differing justice responses from victims' many perspectives and positions? Comparative studies demand more from our research designs and methodologies, we think. Qualitative research is more than interviews, and quantitative research is more than surveys. What can we learn by comparing legal systems and/or by using mixed methods and/or longitudinal panels (Holder, 2018b)? How does our sampling influence the research outcomes? While there have been reviews looking at particular types of victimization, ${ }^{2}$ perhaps a wider-ranging assessment of current evidence would be useful and may point to some obvious gaps.

\footnotetext{
${ }^{2}$ In relation to justice and gender-based violence see, for example, Mulvihill and Hester (2020).
} 


\section{Linking across knowledge areas}

There is a problem of 'knowledge silos' (McCulloch et al, this volume: 12) in this field of research. We suggest that researchers need to synthesize research findings across victim groups and victimization types. Much research is highly focused and specialized. When, why, and how do victims prioritize justice? And is this different if the victim has a disability or has experienced police brutality or has had their village burned to the ground (Balde and Wemmers, this volume)? Can we compare experiences: how similar are the reasons for non-utilization of the law (Messing et al, this volume) with the reasons victims give for utilization of the law? We need to interrogate our findings across regions and countries: for example, does Kim's assessment hold true outside of the U.S.?

\section{Concluding remarks}

The title of this symposium is 'claiming justice'. As guest editors, our thinking was that this notion of claim could be conceived in different ways. One is the usual conception of it as how individuals or groups might use particular mechanisms or approaches to claiming justice. Another is the nature of the claim: is it a moral claim, a legal one or a political one? For those experiencing the injustice, the act of claiming says that the infraction or violation matters or should matter. It also says that the claimant matters whether individual, group or community. Like any claim made within a political community, it will be contested. This is what happens in a court room. Or in a street protest. Or in someone's living room. Because justice matters. 


\section{References}

Anderton, C. (2014) A research agenda for the economic study of genocide: Signposts from the field of conflict economics. Journal of Genocide Research 16(1): 113-138. DOI:

$10.1080 / 14623528.2014 .878118$

Daly, K. (2017) Sexual violence and victims' justice interests in E Zinsstag and M Keenan (Eds.) Restorative responses to sexual violence: Legal, social and therapeutic dimensions. London: Routledge.

Dawson, M (2012) Intimacy, homicide, and punishment: Examining court outcomes over three decades. Australia and New Zealand Journal of Criminology 45(3): 400-422.

Eastwood, C. (2003) The experiences of child complainants of sexual abuse in the criminal justice system. Trends and Issues 250. Canberra: Australian Institute of Criminology. Englebrecht, C., Mason, D. and Adams, M. (2014) The experiences of homicide victims' families with the criminal justice system: An exploratory study. Violence and victims 29(3): 407421.

Fugate, M., Landis, L., Riodan, K., Naureckas, S., and Engel, B. (2005) Barriers to domestic violence help seeking: Implications for intervention. Violence Against Women 11(3): 290-310. Heap, V. (2020) Exploring the effects of long-term anti-social behavior victimization International Review of Victimology Online publication doi.org/10.1177/0269758020961979 Herman, J. (2005). Justice from the victim's perspective, Violence Against Women 11(5): 571602.

Hodžić, R (2010) Living the legacy of mass atrocities: Victim perspectives on war crimes trials. Journal of International Criminal Justice 8: 113-136. 
Holder, R. (2018a) Just interests: Victims, citizens and the potential for justice. Cheltenham: Edward Elgar.

Holder, R. (2018b) Untangling the meanings of justice: A longitudinal mixed methods study. Journal of Mixed Methods Research 12(2): 204-220.

Holder, R. and Daly, K. (2018) Sequencing justice: A longitudinal study of justice goals of domestic violence victims. British Journal of Criminology 58(4): 787-804.

Karstedt, S. (2017) Credible justice and incredible crimes in C Brants and S Karstedt (Eds.) Transitional justice and the public sphere: Engagement, legitimacy and contestation. Oxford: Hart Publishing.

Karstedt, S. (2013) Contextualizing mass atrocity crimes: Moving toward a relational approach. Annual Review of Law and Society 9: 383-404.

Laxminarayan, M., Bosmans, M., Porter, R. and Sosa, L. (2013) Victim satisfaction with criminal justice: A systematic review. Victims and Offenders 8(2): 119-147.

Mahuteau, S. \& Zhu, R. (2016) Crime victimisation and subjective well-being: Panel evidence from Australia. Health Economics 25(11): 1148-1463.

Mulvihill, N. and Hester, M. (2020). Models of justice in P. Davies and M. Rowe (Eds.) Criminology. London: Sage.

Nussbaum, M. and Sen, A. (1993) (Eds.) The quality of life. Oxford: Oxford University Press. Rafferty, J. (2018) "I wanted them to be punished or at least ask us for forgiveness": Justice interests of female victim-survivors of conflict-related sexual violence and their experiences with gacaca. Genocide Studies and Prevention: An International Journal 12(3): 95-118. 
Ren, X. (2014) Legal protection and assistance for victims of human trafficking in the United States: A harm reduction approach in I Vanfraechem, A Pemberton and F Ndahinda (Eds.) Justice for victims: Perspectives on rights, transition and reconciliation. London: routledge. Robinson, A (2014) Pie in the sky? The use of criminal justice policies and practices for intimate partner violence in $\mathrm{H}$ Johnson, B Fisher and V Jaquier (Eds.) Critical issues on violence against women: International perspectives and promising strategies. London: Routledge.

Robinson, A. and Hudson, K. (2011) Different yet complementary: Two approaches to supporting victims of sexual violence in the UK. Criminology \& Criminal Justice 11(5): 515533

Sen, A. (2009) The Idea of Justice, Cambridge: The Belknap Press of Harvard University Press. Shapland, J., Willmore, J. and Duff, P. (1985) Victims in the criminal justice system. Aldershot: Gower Publishing.

Skitka, L., Aramovich, N., Lytle, B. and Sargis, E. (2010) Knitting together an elephant: An integrative approach to understanding the psychology of justice reasoning in R. Bobocel, A. Kay, M. Zanna, and J. Olson (Eds). The Psychology of Justice and Legitimacy: The Ontario Symposium (Volume 11), 1-26. Psychology Press.

Stover, E. and Weinstein, H. (2004) My neighbor, My Enemy: Justice and community in the aftermath of mass atrocity. London: Cambridge University Press.

Swift, A. (2014) Political philosophy: A beginners' guide for students and politicians $\left(2^{\text {nd }} \mathrm{Ed}\right)$ Bristol: Polity Press.

Van Dijk, J., van Kesteren, J. and Smit, P. (2007) Criminal victimization in international perspective: Key findings from the 2004-2005 ICVS and EU ICS. WODC: Netherlands. 